\title{
University Thought and Politics Teaching Based on Humanistic Quality Education
}

\author{
$\operatorname{Lin} \mathrm{Xu}$
}

\author{
Jiangxi Vocational Techlege Of Industry \& Trade, Jiangxi, Nanchang,330038 \\ 739960103@qq.com
}

\begin{abstract}
With the deepening of china's higher education reform, the importance of humanistic quality education gradually appears, the university wants to train all-round development of high-quality personnel, it can not be separated from the humanities quality education. General Secretary Xi Jinping pointed out that Lideshu people should be integrated into ideological and moral education, cultural knowledge education and social practice education. Humanistic quality education is the direction of the goal of Liddeshu people. Humanities quality education can improve the comprehensive quality of college students and cultivate their excellent quality. Based on the humanistic quality education, this paper analyzes the current situation of thought and politics teaching in contemporary universities, and makes suggestions for the strengthening of humanistic quality education in the teaching of humanistic quality in university thinking and politics.
\end{abstract}

Keywords : Humanities quality education, University education, Thought politics teaching

\section{基于人文素质教育的大学思政教学}

徐琳

\author{
江西工业贸易职业技术学院 江西 南昌 330038 \\ 739960103@qq.com
}

\section{摘要}

随着我国高等教育改革的深入, 人文素质教育的重要性逐渐显现出来, 大学想要培养出全方位发展的高素质人 才, 就离不开人文素质教育。习近平总书记指出, 要把立德树人融入思想道德教育、文化知识教育、社会实践 教育各环节。人文素质教育就是立德树人目标的实现方向。人文素质教育能够提高大学生的综合素质, 培养学 生优良品质。本文就人文素质教育出发, 分析当代大学的思政教学现状, 为人文素质教育在大学思政教学中的 加强提出建议。

关键词: 人文素质教育; 大学教育; 思政教学

\section{1. 人文素质概述}

人文从字面上理解便是关于人类的文化。而人文 素质指的是人们在人文方面所具有的综合品质或达 到的发展程度。人文素质中有着关注人生命、价值和 意义的人本主义, 也有着价值理性与目的理性, 还有 着理想主义与浪漫主义。人文素质中蕴含着对学生道 德品质、文化素养、理性认识和追求理想方面的要求。 拥有人文素质就必须学会理性认识历史、拥有科学的 认识论与方法论和尊重他人。人文素质的核心就是以 人为本, 体现在人对身边事物的思考上, 一个拥有优

秀人文素质的人在面对事物或问题使，有着理性的思 考习惯, 能够从各个角度进行分析与反思, 对生活有 着积极的态度。

人文教育需要从对学生历史教育、哲学教育、艺 术教育等方面开始培养, 使学生形成对世界的基本认 识。接着要对学生进行文化教育, 使得学生对民族文 化、传统文化产生共鸣, 并将这些文化吸收进去, 成 为自己世界观、价值观、人生观的一部分。然后要进 行人类意识教育, 让学生将自己与人类产生联系, 具 备人类共同体理念，学会与人和谐相处、与自然和谐 相处。最后要进行精神修养的教育，从整体上抬高思 想境界与精神修养，树立一个高尚品德。这四个步骤 
可以将对学生的人文教育从自我认识到与世界相处 再返回到自我信念提升, 由浅入深循序渐进地进行, 使学生最后形成完整优秀的人文素质。人文素质的形 成要依靠后天的人文教育, 学校在其中需要担负起重 要责任。

\section{2. 大学思政教学现状}

\section{1. 网络使学生思想政治状况出现问题}

由于社会经济与科技的不断发展, 当前许多学生 都成长于互联网时代, 他们不像 90 年代或 80 年代的 学生一样生长环境单纯, 在构建三观的时候对外界的 认识全然来自于家长与教师。现在的学生在构建三观 的时候网络给他们带来的影响巨大, 虽然总体呈现出 的思想政治状况依然是积极向上的, 但由于网络信息 繁杂, 他们对网络信息的吸收能力很强, 但是缺乏对 信息的篮选能力, 同时网络的匿名性也让学生在网络 上没有束缚感, 可以随意发表自己的观点, 缺少道德 的约束, 长此以往还是会存在着不同程度的对政治信 仰的模糊与迷茫、心理素质较差、社会责任感缺乏、 团队精神较弱等等问题, 这些问题的出现对大学思政 教学改革提出了要求。

表 1: 大学生网络行为调查

\begin{tabular}{|c|c|c|c|c|c|}
\hline $\begin{array}{c}\text { 网 } \\
\text { 络 } \\
\text { 行 } \\
\text { 为 }\end{array}$ & $\begin{array}{c}\text { 网络社 } \\
\text { 交 }\end{array}$ & $\begin{array}{c}\text { 网络游 } \\
\text { 戏 }\end{array}$ & $\begin{array}{c}\text { 网上学 } \\
\text { 习 }\end{array}$ & $\begin{array}{c}\text { 获取信 } \\
\text { 息 }\end{array}$ & 其他 \\
\hline $\begin{array}{c}\text { 所 } \\
\text { 占 }\end{array}$ & & & & & \\
$\begin{array}{c}\text { 百 } \\
\text { 分 } \\
\text { 比 }\end{array}$ & $34.3 \%$ & $48.9 \%$ & $12.2 \%$ & $53.0 \%$ & $10.5 \%$ \\
\hline
\end{tabular}

\section{2. 学校对思政教育重视度不足}

习近平总书记曾提出, 思政课是落实立德树人根 本任务的关键课程。高校虽然认识到思政教学对大学 生教育来讲的重要性, 但在实际教学之中, 将教育部 对思政教学的意见抛于脑后, 思政教育中的形式主义 十分明显, 许多学校只是通过学校内张贴海报来提升 校园内的思政教育氛围。为了减少教学中的麻烦, 高 校没有对思政教学进行深入的改革, 思政教学的质量 并没有提升。许多高校依然使用着传统的教学方式, 将教学的重点放在了对学生专业知识和智力的培养 上, 忽略了对学生思想政治素养的教育。思政教师也 对思政课程不上心，在课堂上只是将课本内容讲述一 遍, 没有现实案例与课堂互动的加入, 课堂氛围死气 沉沉, 学生在课堂之上也没精打采, 对思政知识提不 起兴趣。思政课程的考核体系也比较单一, 仅仅以期 末考试成绩来对学生的学习成果进行评价, 这也促使 了学生只是在考试前进行刻板的背诵, 没有对思政知 识有深入的了解。高校和教师对思政教学的不重视, 导致了校园内思想政治工作无法很好地全面开展, 不
利于提高学生的综合素质和思想道德水平。

\section{3. 缺少明确教育方向与教育目标}

教学目标是教师进行教学的前提, 决定了教师教 学的方向。教学目标的不明确会导致教师的思政教学 无法顺利开展, 也不能准确对教育方式进行创新。对 大多数高校来说, 思政教学只是一个必须要完成的任 务, 并没有确立对学生的思想政治教学要达到的目标, 所以教师在教学中也只好一直按照传统的方式进行 教学。同时, 由于学校对思政教学的忽视, 思政教师 的综合素质不高, 教师在教学过程之中, 不懂得如何 用高效的方式对学生的思想道德品质进行正确引导, 仅仅是依靠课本上的知识对学生进行灌输式的教学。 教学目标的缺失让高校与教师对思政教学无法进行 深入改革, 思政教学工作也只好停留在传统方式教学 上。

\section{3. 人文素质教育出现的问题}

\section{1. 将学习功利化}

许多大学生学习的出发点并不是因为对知识的 好奇和探究, 而是由于对高薪工作的渴望, 在学习过 程之中将利益放在第一位, 带着功利心进行学习, 对 于那些提高自己思想境界和审美层次的知识文化一 律不感兴趣。为了在教师面前留下好印象, 利用作弊、 请人代考等不好的手段提升成绩, 竞争心极强。

\section{2. 艺术修养与审美能力缺失}

人的审美水平决定了认知水平的高低, 许多当代 大学生无法欣赏事物的美好, 缺少了对身边细微小事 的观察, 审美的缺失也就说明了他们对世界的认知水 平并不高, 人文素养也就由此体现。现在的大学生在 学习时更加偏向职业技能的学习, 经常忽视了文学和 艺术方面的能力提高。这样虽然给国家和企业提供了 众多技术型人才, 但他们的综合素质并不高, 在实际 工作中也会面对许多困难。现在大学生虽对自己学习 的专业知识如数家珍, 但对于哲学、文学、历史方面 的知识并不了解, 现在大学专业中工科专业极受欢迎, 但文科专业已经逐渐势弱。甚至整个社会都呈现出重 理轻文的状态, 使得社会人心越来越浮躁。

\section{3. 价值观与世界观偏离}

现代大学生的价值观中存在着个人主义的思想, 遇到事情将自己的利益放于首位，不愿意去关心与帮 助他人, 对集体活动没有积极性, 狭险的个人主义与 小团体意识比较明显。许多学生树立自己的价值观与 世界观时, 将自我放在了首位, 而不去关注与社会、 与世界的联系, 缺乏理想与信念。许多学生在学习思 政课程之后, 虽对马克思主义哲学和中国政策有了一 定的了解, 但还是无法学习到中国传统文化中蕴含的 
道德品质。现在大学生的价值取向虽偏向多元化, 但 其中的个体性特征十分明显, 相较于团队和社会的幸 福安稳, 更加注重个人的成功。

在商品经济的冲击之下, 学生群体之中出现了拜 金主义现象, 有个别大学生崇尚着金钱至上的原则, 行为处事都以利益为主导，用金钱来评价他人，用金 钱作为人生价值的衡量标准, 对中国传统优良文化十 分漠视。有部分学生还对偶像崇拜有偏离, 对偶像的 选择不按照品德的好坏来进行挑选, 而是遵循着容貌 至上的原则, 此种观念也渐渐渗透到学生的日常生活 中去。

\section{4. 人文素质教育缺失原因}

\section{1. 社会的影响}

随着我国经济的不断发展, 大众的生活质量得到 了改善, 但伴随而来的便是精神文明建设与物质生活 提高之间的不平衡, 科技的发展反而使社会的人心变 得浮躁。改革开放之后给人们带来了众多的物质利益, 在物欲冲击之下, 许多人不能正确地面对社会发展所 带来的负面影响, 使得社会中享乐主义滋生。现在的 大学生大多都是独生子女, 家庭条件比较好, 生活中 也被家长宠爱, 其心中的个人主义观念逐渐在这样的 家庭成长过程之中养成。

同时随着社会的发展, 知识更新的速度在不断加 快, 并且知识传播的渠道十分多样化, 学生对知识的 获取更加轻松且自主和开放, 在社会功利性越来越强 的现在, 学生在想要获取的信息中更加偏向于功利性 和实用性, 以便在毕业之后能够找到更好的工作, 而 马克思主义哲学、毛泽东思想等等这类知识, 对于学 生来说实用性不强, 于是在学习的过程之中学生只将 及格作为学习思政课的目标。

\section{2. 学校教育失衡}

现在许多高校为了满足企业对人才的需求和提 高学校知名度, 十分急功近利, 将专业教学摆在第一 位, 而忽视了人文素质教育, 使得学生个人发展不平 衡。现在高校中思政课程是作为辅修课程而存在的, 由于其普遍性, 许多学校会将思想政治教育默认低于 专业教育, 在活动举办、教师安排等等方面把专业教 学放在思政教学之前, 但大学生思想政治状况是他们 安身立命之本, 人文素质教育的缺失会让大学生在进 入社会以后缺少学习生活的可持续性。高校教育重视 实用性知识, 想要培养出职业型人才并没有错, 但对 思想政治教育的忽视是不应该的, 不树立学生正确的 人生观、价值观、社会观, 是无法将学生培养成为国 家与社会需要的高素质人才的。

\section{3. 教师认识不足}

教师是课堂之中的引导者, 思政教育的效果如何,
其决定性因素就是教师的教学能力。现在许多思政教 师对课程的重视程度不高, 也不考虑培养学生的人文 素质, 在课程之上一直沿用传统的教学方式, 让学生 对课程提不起兴趣。现在许多高校之中师资力量不足, 这也就迫使学校在课程安排上将思政课调整为上百 人的大课, 一位教师面对这么多的学生, 在教学过程 中难免力不从心, 无法完全发挥教学效果。还有一些 思政教师本身的人文素养知识就不够, 且对人文素质 没有清晰了解, 认为人文素质教育在思政教学中不重 要, 没有能力也不想投入精力对学生进行人文素质知 识的教学。

\section{4. 人文素质教育方式存在不足}

许多思政教师在教学之中意识到了人文素质教 育的重要性, 但没有根据现实情况来对教学方式进行 创新改革。许多教师在进行人文素质教育时依旧是使 用的老办法, 对知识进行刻板单调的宣讲, 使用灌输 式的教学方式试图将知识强塞给学生, 课堂之上没有 师生之间的互动, 这样的教育方式不仅使得学生对课 程内容不感兴趣, 更是会渐渐地打击教师的教学热情。 教师在这种教育方式之下, 会发现自己在课程中增加 的人文素质教学起不到对学生的教育作用, 无法得到 很好的教学效果。

\section{5. 落实有困难}

人文素质教育的效果很难有一个明确的评判标 准, 这也就让学校对学生的人文素质教育难以落实。 大部分学校对学生的思政学习评价是以单一的课堂 测试为标准, 于是许多教师在教学时关注的是学生最 后考试成绩的展现, 甚至有教师为了考试成绩表现优 异, 会给学生进行透题, 让学生有针对性地复习, 以 求最终成绩能够应付学校。人文素质教育在最终落实 方面存在的问题会让人文素质教育无法发挥作用, 学 生的人文素质得不到实质性的提高。

\section{5. 培育大学思政教学中人文素质教育途径}

\section{1. 发挥高校思政课程作用，改进教学方式}

高校要认清思政教育在高校教育体系中的基础 位置, 平衡教学中的思政教学和专业教学, 提升思政 教学的重要性。学校要在思政教学之中强调人文素质 教育的作用, 引导学生价值取向, 以养成学生优秀品 格为教学目标, 充分发挥思政课作用。教师要对教学 方式进行创新, 在课堂之上不能再采取以往传统的教 学方式, 要在思政课堂上增加人文素质知识的教学, 在教学过程中代入历史真实事件, 引导学生进行思考, 提升学生的积极性。教师还可以设计一些课堂活动, 增加师生互动, 活跃课堂氛围。 


\section{2. 组织校内与校外实践活动}

人文素质的培养光靠课堂上理论知识的学习时 不够的, 教师在课堂上的讲解是平面的, 对学生来说 不够全面, 人文素质教育可以实践活动之中得到充分 体现。实践活动的增加可以让学生将人文素质知识内 化为内心坚定的信仰, 进而将个人的道德品质外化为 行动, 成为实干者, 而不是纸上谈兵的 “理论家”。 高校要结合当下, 经常组织思政相关的活动, 比如在 建党 100 周年之际, 举办红歌合唱、诗歌朗诵等活动, 通过这个机会塑造校园内的人文素质教育氛围, 提升 学生的综合素质水平。高校也要引导学生参加各类志 愿活动或党组织活动, 通过奖励学分、张贴海报、教 师宣传等方式鼓励学生参加, 丰富学生的课余生活, 拓宽学生生活与学习的视野, 陶冶学生的情操。学校 也可以组织学生集体去往红色基地或是鼓励学生进 入社会进行校外实践, 锻炼学生思考和解决问题的能 力, 提升他们的人文素养。

\section{3. 互联网与思政课程相结合}

现在是互联网的时代, 我们身边的万事万物都离 不开网络, 许多教育领域也在不断进行与互联网之间 的联系与合作, 教师也要客观地看待网络, 在课堂上 充分发挥网络的作用, 利用网络上下载的历史图片、 纪录片、电影, 加深学生的思政认识, 提升学生的审 美素质。同时教师也应该在课堂上教会学生网络信息 的笁选, 避免学生在网络上接触到不好的信息, 让网 络对学生的不利影响降到最低。

同时教师可以通过学校新媒体账号建设来对学 生进行全方位的人文素质教育。新媒体作为互联网发 展的产物, 许多学生会在新媒体平台中获取信息和知 识, 学校可以在学生经常汶览的新媒体平台设立账号, 并在账号上市场分享一些有趣的人文知识, 借此平台 来对学生进行人文素质教育。比如学校可以在微博、 微信公众号、抖音等平台设置账号, 在账号上开设“革 命今时今日” 栏目, 在这个栏目上分享历史中本日发 生的历史事件。账号内还可以开设 “人文校园圈” 栏 目可以通过宣传校园内发生的轶事, 或者与学校教师、 优秀的毕业生有关的事件来加强学生的人文素质教 育。这样的平台方便学生之间进行互动交流, 并且可 以直观地感受到优秀的学习榜样, 以此来提升学生的 人文素质。

\section{4. 完善思政课程评价体系}

学校设立科学合理的针对人文素质的考核评价 体系有利于激发学生对于学习的兴趣。学校应在课程 评价体系中增加有关人文素质的考核, 并且拓宽考核 渠道, 不要只将思政评价体系束缚于课堂测评中。学 校要在课程评价体系中深化人文素质教学改革, 通过 此体系体现人文素质教育质量的提升, 增强教育的效 果, 促使学生追求知识、素质、能力三方面全面协调
发展。学校完善思政课程评价体系应该要注重其具体、 可操作性性、层次性。高校思政课程评价体系中可以 增加学生实践活动评价、课堂表现评价等等, 从多方 面多层次对学生进行评价。

\section{6. 结论:}

高校教育不仅要注重对学生科学知识方面的培 养, 还要积极促进学生人文素质的提高。人文素质决 定了一个人看待世界的角度和为人处世的方式, 高校 想要培养出高素质的人才, 就不能忘记人文素质教育 的重要性。高校需要继续加深思政教学改革, 坚定奉 行思政教育的 “八个统一”，总结过往思政课经验， 不断加深思政课程的思想性、针对性和实践性。

\section{REFERENCES}

[1] Xie Xiaoyu, Wang Longchang. Mining the ideological and political elements and instructional design of agricultural extension course based on massive open online course $[\mathrm{J}]$. Journal of Southwest Normal University (Natural Science Edition), 2021,46(08):132-139.

[2] Li Jun. Research on the status quo and reform and innovation of practical teaching of ideological and political courses in higher vocational colleges from the perspective of informationization [J]. Modern Vocational Education, 2021,\{4\}(30):226-227.

[3] Yu Lianbo, Ren Nianwen. The path of improving the education mechanism of ideological and political courses in colleges and universities in the new era [J]. Journal of Heilongjiang Teachers Development College, 2021,40(07):56-58.

[4] Jiang Hua. Analysis on the special teaching of ideological and political theory course in higher vocational colleges — Taking "Introduction to Mao Zedong Thought and Theoretical System of Socialism with Chinese Characteristics" as an example [J]. Journal of Heilongjiang Teachers Development College, 2021,40(07):65-67.

[5] yuan haojie. the subjective and objective dispute of comprehensive quality evaluation-the contest between humanistic evaluation and scientific evaluation $[\mathrm{J}]$. survey of education, 2021,10(23):67-70.

[6] Xie Xiaojuan. All-round development of Marxist people and humanistic quality education of college students [D]. Southwest University, 2013. 